\title{
Triiodothyronine levels were positively correlated with opening of collateral circulation in cerebral infarction patients with large artery atherosclerosis
}

\author{
Xiao-Feng Dong ${ }^{1}$, Fan-Zhen Kong ${ }^{2}$, Ming-Qiang Shen ${ }^{1}$, Jiang Huang ${ }^{3}$, Zong-En Gao ${ }^{4}$, \\ Qian-Zhu Guo ${ }^{1}$, Zhong Zhao', Wei-Feng Luo ${ }^{5}$, Qing-Zhang Cheng ${ }^{1}$, Guan-Hui Wu ${ }^{1}$
}

\begin{abstract}
${ }^{1}$ Neurology Department, Suzhou Municipal Hospital, Affiliated Suzhou Hospital of Nanjing Medical University, Suzhou, China

${ }^{2}$ Department of Psychology, Suzhou Guangji Hospital, Suzhou Psychiatric Hospital, Suzhou, China

${ }^{3}$ Ophthalmology Department, Second Affiliated Hospital of Soochow University,

Suzhou, China

${ }^{4}$ Neurology Department, Shengli Oilfield Central Hospital, Suzhou, China

${ }^{5}$ Neurology Department, Second Affiliated Hospital of Soochow University, Suzhou, China
\end{abstract}

Submitted: 25 May 2017

Accepted: 21 July 2017

Arch Med Sci 2020; 16 (1): 51-57

DOI: https://doi.org/10.5114/aoms.2020.91286

Copyright @ 2019 Termedia \& Banach

\section{Abstract}

Introduction: Non-thyroidal illness syndrome (NTIS) is one of the signs for poor prognosis of cerebral infarction $(\mathrm{Cl})$, but its risk factors had never been explored. In this study, we analyzed the potential effect of collateral circulation on prognosis prediction of triiodothyronine for large artery atherosclerosis cerebral infarction (LAA-CI) patients.

Material and methods: Clinical data of $\mathrm{Cl}$ patients between 2012 and 2014 were collected. Imaging inspection was used for determining TOAST classification and evaluating collateral circulation. One-year follow-up was conducted for mRS score by telephone.

Results: T3 level in the NTIS group $(p=0.001)$ was significantly decreased while TSH level $(p<0.001)$ was increased. Patients in the NTIS group had a poorer prognosis $(p=0.008)$ and the main reason was the high mortality $(p=0.002)$. NTIS predicted poor collateral circulation $(p=0.026)$ and good collateral circulation tended to be less likely concomitant with NTIS $(p=0.001)$. Logistic regression analysis showed that triiodothyronine concentrations $(\mathrm{OR}=4.760,95 \% \mathrm{Cl}: 1.981-11.456, p<0.001)$ were positively correlated with but advanced age $(\mathrm{OR}=0.756,95 \% \mathrm{Cl}: 0.645-0.886, p=0.001)$ negatively with opening of collateral circulation.

Conclusions: Poor opening of collateral circulation was likely to mediate the prediction of NTIS for prognosis of LAA-CI patients.

Key words: cerebral infarction, non-thyroidal illness syndrome, collateral circulation, prognosis.

\section{Introduction}

Non-thyroidal illness syndrome (NTIS), part of the neuroendocrine response to stress, is a state of adaptation or dysregulation of thyrotropic feedback control where the levels of triiodothyronine (T3) and free triiodothyronine (fT3) are at unusual levels, but the level of thyroid-stim-

\author{
Corresponding author: \\ Guan-Hui Wu MD, Ph.D \\ Neurology Department \\ Suzhou Municipal Hospital \\ Affiliated Suzhou Hospital \\ of Nanjing Medical \\ University \\ 26 Daogian St \\ Gusu District \\ 215002 Suzhou, China \\ Phone: +86-18061924176 \\ E-mail: ghwusz@163.com
}


ulating hormone (TSH) is normal. Apart from severe illness and surgery, NTIS is also common in old patients with risk factors for cardiovascular disease [1-3]. NTIS is one of the signs for poor prognosis in patients with cerebral infarction $(\mathrm{Cl})$ [4-6], but its related influencing factors had never been explored. In a previous study, we found that large artery atherosclerosis cerebral infarction (LAA-CI) patients with NTIS had more severe neurological deficits [7]. In this study, we mainly investigated the potential effect of collateral circulation on prognosis prediction of triiodothyronine in LAA-Cl patients, which would provide a guideline for the treatment and prognosis prediction of $\mathrm{Cl}$.

\section{Material and methods}

\section{Study subjects}

Thyroid function test information of $\mathrm{Cl}$ patients admitted to our hospital between 2010 and 2012 was collected. A total of 208 patients (132 male and 76 female) aged 48-94 year old were divided into a control group $(n=151)$ and an NTIS group $(n=57)$. The diagnosis criteria for $\mathrm{Cl}$ referred to "Guidelines for the early management of patients with acute ischemic stroke: a guideline for healthcare professionals from the American Heart Association/American Stroke Association" [8]. Excluded were patients with history of chronic thyroid diseases, history of taking drugs harmful to thyroxine, non-acute phase of $\mathrm{Cl}$, brain tumor, encephalitis, brain injury and severe multi-organ dysfunction. This study was approved by the Ethics Committee of Suzhou Hospital Affiliated to Nanjing Medical University.

\section{Examination on admission and evaluation}

Known history of smoking, hypertension, diabetes mellitus and coronary heart disease were collected when patients were admitted to hospital. NIHSS score was evaluated according to patients' symptoms and signs. Fasting venous blood samples were collected within $24 \mathrm{~h}$ after admission for the measurement of biochemical index. Radioimmunoassay was performed to measure the levels of triiodothyronine (T3), total thyroid hormone (T4), thyroid-stimulating hormone (TSH), free triiodothyronine (fT3) and free thyroid hormone (fT4), with T3 $<1.21 \mathrm{nmol} / \mathrm{l}$ or $\mathrm{fT} 3<2.63 \mathrm{pmol} / \mathrm{l}$ as the diagnostic criteria of NTIS [4]. Magnetic resonance imaging (MRI), magnetic resonance angiography (MRA), computed tomography angiography (CTA) and digital subtraction angiography (DSA) were used for determining TOAST classification, selecting patients with $\mathrm{LAA}-\mathrm{Cl}$ and evaluating collateral circulation. Imaging examination with prominent laterality of adjacent vessel on 3D TOF MRA or with hyperintense vessel on FLAIR MR was identified as opening of collateral circulation [9]. One-year follow-up was conducted in 170 patients (38 patients lost to follow-up) for mRS scores. Parts of characteristic indexes were stratified based on previous studies [10-12]. Prognosis with modified Rankin score (mRS): 0-2, good; 3-6, poor; 6 meaning death [7].

\section{Statistical analysis}

Continuous data in normal distribution were expressed as mean \pm standard deviation and analyzed by $t$ test. Continuous data in non-normal distribution were expressed as median and compared using the Mann-Whitney $U$ test. Univariate analysis of categorical data (expressed with percentage) was performed using the $\chi^{2}$ test. Logistic regression was used to analyze the influencing factor for NTIS, with $p<0.05$ indicating a significant difference.

\section{Results}

Univariate analysis on baseline data of the two groups showed that age, the ratio of patients with diabetes, systolic pressure and NIHSS scores at admission were higher in the NTIS group than in the control group $(p<0.05)$. The ratio of patients with collateral circulation opening was lower in the NTIS group than in the control group $(p<$ $0.05)$. Prognosis analysis showed that patients in the NTIS group had poorer prognosis ( $p=0.008$ ) and the main cause was the higher mortality $(p=0.002)$ (Table I).

As compared with the thyroid hormone level, T3 level in the NTIS group was lower than that in the control group $(p=0.001)$ while TSH level was higher than that in the control group $(p<0.001)$ (Table II).

Patients with collateral circulation opening had lower incidence of NTIS ( $p=0.001$, Figure $1 \mathrm{~A})$ and patients with NTIS had a lower rate of collateral circulation opening ( $p=0.026$, Figure 1 B). Magnetic resonance imaging showed that patients with good collateral circulation had a smaller infarction lesion (Figures $2 \mathrm{~A}$ a and b) than patients with poor collateral circulation (Figures $2 \mathrm{~B}$ a and b). Compared with all patients, $T 3$ level was not markedly increased in patients with good collateral circulation (1.36 \pm 0.28 vs. $1.32 \pm 0.38, n=56,208$, $p=0.231$, Figure $2 \mathrm{Ac}$ ) while it was significantly lower in patients with poor collateral circulation $(1.29 \pm 0.41$ vs. $1.32 \pm 0.38, n=152,208, p=0.014$, Figure 2 B c).

Logistic regression showed that $\mathrm{T} 3$ levels $(\mathrm{OR}=$ $4.760,95 \% \mathrm{Cl}: 1.981-11.456, p<0.001)$ were positively but age $(\mathrm{OR}=0.756,95 \% \mathrm{Cl}: 0.645-0.886$, $p=0.001$ ) inversely correlated with the opening of collateral circulation (Table III). 
Table I. Demographic data and prognosis for patients with or without NTIS

\begin{tabular}{|c|c|c|c|c|}
\hline Parameter & Control $(n=151)$ & NTIS $(n=57)$ & Test value & $P$-value \\
\hline Age & $69.05 \pm 12.10$ & $77.00 \pm 10.39$ & -4.384 & $<0.001$ \\
\hline Gender (male) & $99(65.56)$ & $33(57.89)$ & 1.049 & 0.306 \\
\hline Smoking & 59 (39.07) & $20(35.09)$ & 0.279 & 0.597 \\
\hline Stroke history & $19(12.58)$ & $3(5.26)$ & 2.344 & 0.126 \\
\hline Hypertension & $121(80.13)$ & $47(82.46)$ & 0.144 & 0.704 \\
\hline Diabetes & $56(37.09)$ & $31(54.39)$ & 5.090 & 0.024 \\
\hline $\mathrm{CHD}$ & $12(7.95)$ & $6(10.53)$ & 0.348 & 0.555 \\
\hline Collateral opening & $47(31.13)$ & $9(15.79)$ & 4.947 & 0.026 \\
\hline SBP & $145.73 \pm 45.14$ & $155.67 \pm 23.52$ & -2.063 & 0.040 \\
\hline DBP & $78.69 \pm 25.02$ & $80.37 \pm 14.20$ & -0.478 & 0.633 \\
\hline $\mathrm{HbA}_{1 \mathrm{c}}$ & $7.13 \pm 2.13$ & $7.50 \pm 1.82$ & -0.893 & 0.373 \\
\hline LDL & $2.71 \pm 1.41$ & $2.97 \pm 1.29$ & -1.212 & 0.227 \\
\hline Albumin & $36.41 \pm 8.30$ & $35.62 \pm 5.84$ & 0.660 & 0.510 \\
\hline NIHSS at admission & $4.00(2.75,6.00)$ & $6.00(4.00,10.00)$ & -3.497 & $<0.001$ \\
\hline \multicolumn{5}{|l|}{ mRS: } \\
\hline $0-2$ & $79(52.32)$ & $22(38.60)$ & 3.119 & 0.077 \\
\hline $3-5$ & $34(22.52)$ & $16(28.07)$ & 0.699 & 0.403 \\
\hline 6 & $8(5.30)$ & $11(19.30)$ & 9.772 & 0.002 \\
\hline $3-6$ & $42(27.81)$ & $27(47.39)$ & 7.137 & 0.008 \\
\hline
\end{tabular}

Table II. Comparison of thyroid hormones between NTIS group and control group

\begin{tabular}{|lcccc|}
\hline Parameter & Control $(n=151)$ & NTIS $(n=57)$ & $Z$ value & $P$-value \\
\hline T3 & $1.33(1.23,1.56)$ & $1.05(0.91,1.14)$ & -3.459 & 0.001 \\
\hline fT3 & $4.04(3.64,4.36)$ & $3.29(2.66,3.64)$ & -1.895 & 0.058 \\
\hline T4 & $76.65(56.32,95.68)$ & $82.58(70.73,94.44)$ & -0.097 & 0.923 \\
\hline fT4 & $14.16(12.94,15.28)$ & $13.91(13.29,15.02)$ & -0.382 & 0.702 \\
\hline TSH & $1.34(0.86,2.69)$ & $1.59(0.79,2.40)$ & -7.848 & $<0.001$ \\
\hline
\end{tabular}

\section{Discussion}

NTIS is one of the signs of poor prognosis in patients with $\mathrm{Cl}$ [4-6]. Previous studies reported that NTIS was an independent predictor of survival in early and advanced stages in patients with acute infarction and could predict the degree of disability after 1 year $[4,5]$. Compared with patients with the upper tertile of fT3 level, $\mathrm{Cl}$ patients with lower tertiles of fT3 level had higher NIHSS scores, more severe neurological deficits, higher 1-year mortality, increased white blood cell count and higher frequency of ventricular compression [5]. The decreased T3 level also predicted more severe neurological deficits in $\mathrm{Cl}$ patients when discharged from hospital [13]. Administration of TSH within $24 \mathrm{~h}$ after $\mathrm{Cl}$ occurs can reduce the incidence of NTIS and decrease NIHSS scores [14]. T3 can reduce cerebral edema through inhibiting the expression of AQP4 [15]. T3 packaged with nanoparticles reduces the volume of $\mathrm{Cl}$ and cerebral edema and is beneficial for drug performance on neuroprotection [16]. Basic research also found that supplementation of $\mathrm{T} 3$ activates the PI3/Akt kinase pathway and eNOS, which reduces the volume of $\mathrm{Cl}$ in mice with transient focal $\mathrm{Cl}$ and improves neurological deficits [17]. Those studies revealed that the increase of T3 level could improve the prognosis of $\mathrm{Cl}$.

Our previous study found that NTIS could better predict the neurological deficits in patients 
A

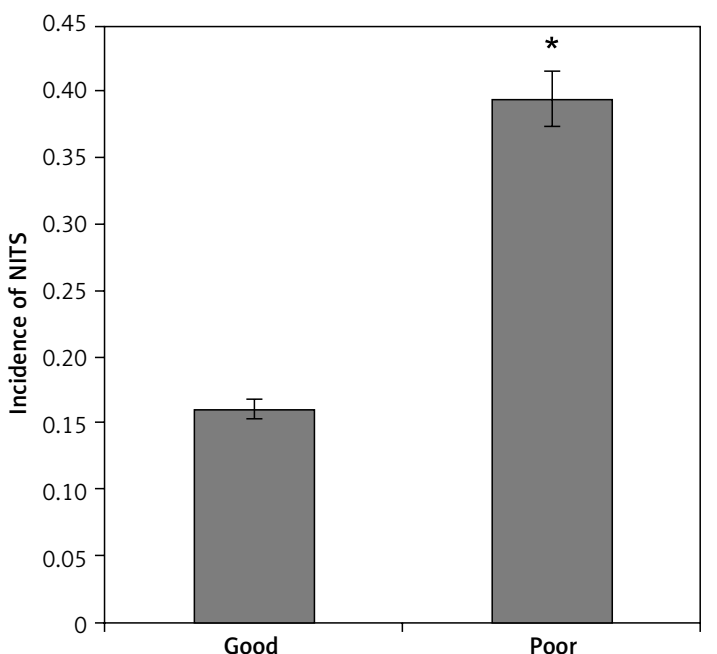

B

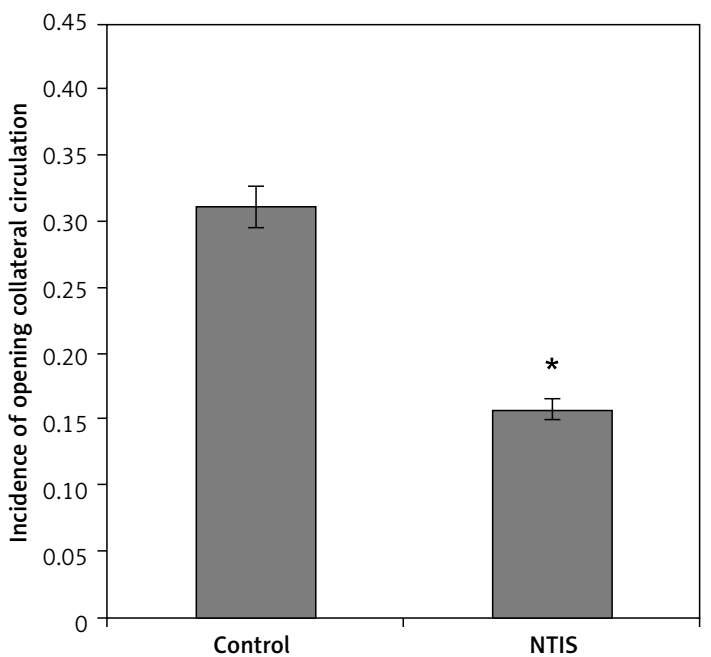

Figure 1. A - Correlation of collateral circulation status with NTIS incidence. A significant difference was found for NTIS incidence between patients in good and in poor collateral circulation status $\left(16.07 \%\right.$ vs. $39.47 \%, \chi^{2}=10.110$, $p=0.001)$ B - Correlation of T3 concentration with collateral circulation status. Lower proportion of good collateral circulation found in NTIS group and higher in control group formed a significant difference (15.79\% vs. $31.13 \%$, $\chi^{2}=4.947, p=0.026$

with $\mathrm{LAA}-\mathrm{Cl}[4]$. A recent imaging study showed that the progression of infarction caused by LAA$\mathrm{Cl}$, especially middle cerebral artery occlusion, is highly heterogeneous $[18,19]$. In some cases, infarction could cause necrosis of the entire brain tissue in the ischemic region within $1 \mathrm{~h}$, while other cases showed evidence of survival of tissues several days after $\mathrm{Cl}$. In patients with proximal arterial occlusion and survival of distal brain tissue, retrograde filling of the pial artery is a marker of collateral circulation opening in angiography. Imaging showed that blood flow through collateral circulation could perfuse brain tissues for several hours after artery occlusion. Hence, maintaining and increasing the blood flow through collateral circulation is a promising way to treat $\mathrm{Cl}$ [19]. The opening of collateral circulation caused by activation of the PI3/Akt kinase pathway and the increased production of nitrogen oxide might be an important mechanism for the treatment with T3 supplementation in $\mathrm{Cl}$ [17]. A previous study reported that lowering the T3 level could affect opening of collateral circulation through changing the distribution and deformability of erythrocytes [20], disturbing the expression of coagulation factors and genes [21-23], injuring vascular endothelial cells, smooth muscle, cardiac systolic and brain function [24-31].

Cheng-Ching et al. found that, in $L A A-C l$ patients, the opening of collateral circulation shown in CTA could better predict the volume of the anterior circulation infarction core area shown in MR-DWI imaging which contributed to identifying the ischemic penumbra urgently needed to be saved $[32,33]$. Fassbender revealed that the vol- ume of $\mathrm{Cl}$ was related to the stress degree of the hypothalamic pituitary axis [34]. Our prior study [7] also found that NTIS could better predict the degree of neurological deficits related to the volume of $L A A-C l$ in the internal carotid artery system, so that the occurrence of NTIS might have a close association with the opening of collateral circulation. Previous studies have never reported the effects of collateral circulation on the prognosis in $\mathrm{Cl}$ patients with NTIS and the association between T3 level and collateral circulation. This study found that patients with opening of collateral circulation had lower incidence of NTIS and a small infarction volume, and patients with NTIS had lower probability of opening collateral circulation and large infarction volume. After adjusting for other confounders such as age, sex and other risk factors for vascular disease, T3 levels were independently associated with opening status of collateral circulation. Recently, Menon et al. [35] reported that collateral circulation assessed by CTA was an independent prognostic predictor for $\mathrm{Cl}$ both with endovascular treatment and with intravenous thrombolysis, which provided evidence consistent with this study that $\mathrm{T} 3$ level and prognosis of $\mathrm{Cl}$ might be linked by opening of collateral circulation.

Age is another influencing factor for collateral circulation in patients with LAA-CI. Among several established risk factors for poor prognosis of ischemic stroke, collateral circulation has risen to the most prominent point with the development of vascular imaging, which proved to be affected by age, especially in patients with a proximal middle cerebral artery [32, 35-37]. On the other hand, with increasing age the production of TSH 

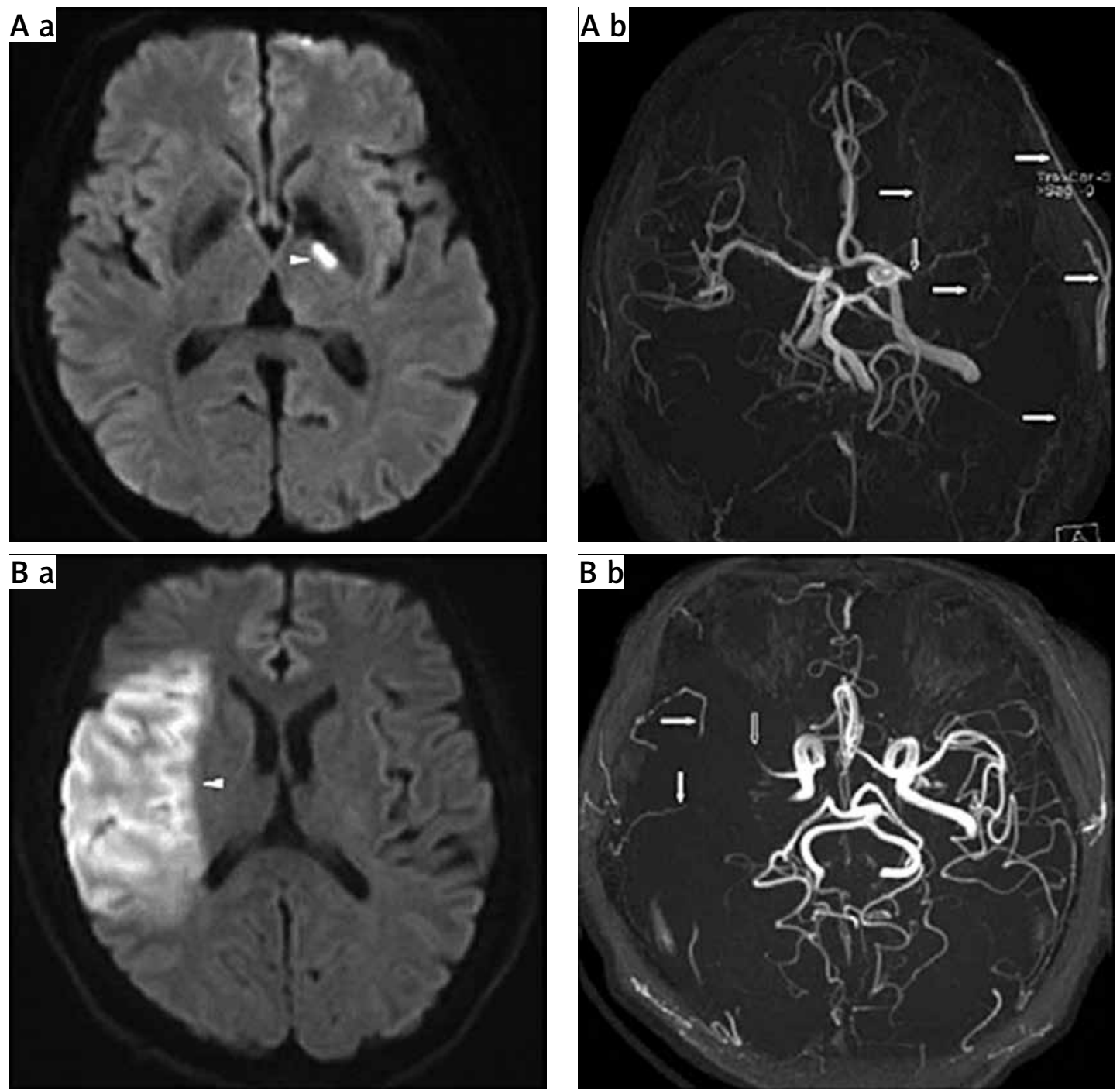

A C

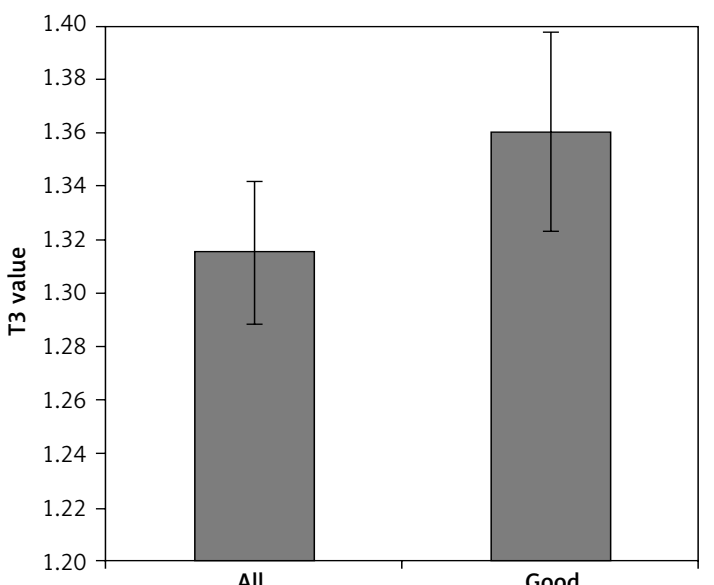

B C

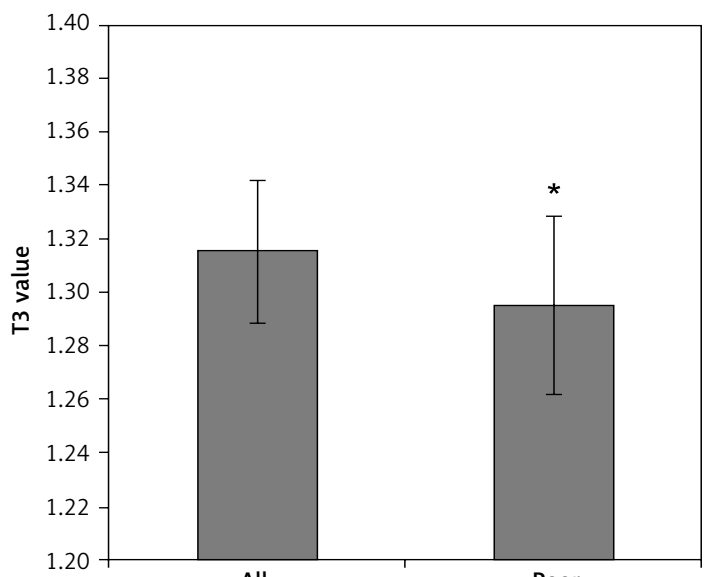

Figure 2. A - Lacunar infarction resulted from left middle cerebral artery occlusion with normal T3 value (1.53 nmo$\mathrm{I} / \mathrm{I})$ and good collateral circulation in a male patient 65 years old $(\mathbf{A} \mathbf{a}$ and $\mathbf{b})$. No significant difference was found for T3 value between good collateral circulation group and all patients ( $1.36 \pm 0.28$ vs. $1.32 \pm 0.38, n=56,208$ respectively, $p=0.231$, A c). Triangle stands for infarction lesions, solid arrows stand for opening collateral circulation and hollow arrows stand for arterial stenosis or occlusion. B - Large infarction resulted from right middle cerebral artery occlusion with low T3 value $(0.98 \mathrm{nmol} / \mathrm{l})$ and poor collateral circulation in a female patient 63 years old (B a and b). A significant difference was found for T3 value between poor collateral group and in all patients $(1.29 \pm 0.41 \mathrm{vs}$. $1.32 \pm 0.38, n=152,208$ respectively, $p=0.014$, B c). Triangle stands for infarction lesions, solid arrows stand for opening collateral circulation and hollow arrows stand for arterial stenosis or occlusion 
Table III. Influencing factors for opening collateral circulation analyzed with logistic regression

\begin{tabular}{|lccc|}
\hline Parameter & OR & $95 \% \mathrm{Cl}$ & $P$-value \\
\hline Age & 0.756 & $(0.645-0.886)$ & 0.001 \\
\hline Triglyceride & 0.502 & $(0.188-1.345)$ & 0.171 \\
\hline Folic acid & 0.424 & $(0.160-1.122)$ & 0.084 \\
\hline T3 & 4.760 & $(1.981-11.456)$ & $<0.001$ \\
\hline
\end{tabular}

was decreased and the threshold of TSH levels to stimulate secretion of thyroid hormone was elevated. The reduction of TSH suggested the decline of hypothalamic-pituitary-thyroid (HPT) axis function [38]. Our study found that age and TSH levels in the NTIS group were significantly higher than those in the control group, while T3 levels were lower than in the control group, which indicated that elevated TSH stimulated by lower T3 levels could not promote the release of thyroid hormones, and further confirmed that the function and feedback decline of HPT failed to accommodate the change of the environment. In consequence replacement therapy was recommended for preservation of target organ function [39, 40]. The results suggested that collateral status and HPT function would keep the synchronous alteration trend and mutual confirmatory interaction varying with age when exposed to stroke stress.

Univariate analysis showed that systolic pressure and NIHSS scores at admission were higher in the NTIS group than in the control group [4]. However, multivariate analyses failed to find their associations with NTIS. Glycosylated hemoglobin $A_{1 c}\left(H b A_{1 c}\right)$ level can reflect the levels of blood glucose before and after the onset [41], but this study did not find an association between $\mathrm{HbA}_{1 \mathrm{c}}$ level and NTIS. The reason may be that NIHSS score and $\mathrm{HbA}_{1 \mathrm{c}}$ level could not reflect infarction volume and stress degree consistently. Systolic pressure might be affected by the change of intracranial pressure, which resulted in the unmatched degree of stress reflected by T3 level.

There are some limitations of this study. Firstly, the resolution of collateral circulation evaluated by MRA is limited. Secondly, the relatively small sample size and patients lost to follow-up may lead to bias in the final results. Thirdly, the mismatch in age and gender could result in deviation of research findings. Fourthly, whether the disturbed thyroid hormones occurred pre- or poststroke was not determined. Thus, a large sample prospective study based on high resolution angiography and more matched data are needed to verify the results.

In conclusion, this study firstly found that T3 level was closely associated with the opening of collateral circulation. Patients with collateral cir- culation opening had lower incidence of NTIS and patients with NTIS had a lower rate of collateral circulation opening. Prognosis analysis showed that patients in the NTIS group had poorer prognosis and the main cause was the high mortality. Clinical physicians can predict the condition of collateral circulation opening and prognosis according to the T3 level in the acute stage in elderly $\mathrm{Cl}$ patients. Actions to maintain or promote the opening of collateral circulation with thyroid hormones may be considered for the improvement of prognosis in those patients.

\section{Acknowledgments}

Xiao-Feng Dong, Fan-Zhen Kong and MingQiang Shen contributed equally to the work.

\section{Conflict of interest}

The authors declare no conflict of interest.

\section{References}

1. de Vries EM, Fliers E, Boelen A. The molecular basis of the non-thyroidal illness syndrome. J Endocrinol 2015; 225: R67-81.

2. Warner $\mathrm{MH}$, Beckett GJ. Mechanisms behind the non-thyroidal illness syndrome: an update. J Endocrinol 2010; 205: 1-13.

3. Zhou Y, Zhao L, Wang T, et al. Free triiodothyronine concentrations are inversely associated with elevated carotid intima-media thickness in middle-aged and elderly Chinese population. J Atheroscler Thromb 2016; 23: 216-24.

4. Alevizaki M, Synetou M, Xynos K, et al. Low triiodothyronine: a strong predictor of outcome in acute stroke patients. Eur J Clin Invest 2007; 37: 651-7.

5. Ambrosius W, Kazmierski R, Gupta V, et al. Low free triiodothyronine levels are related to poor prognosis in acute ischemic stroke. Exp Clin Endocrinol Diabetes 2011; 119: 139-43.

6. Forti P, Maioli F, Coveri M, et al. Thyroid function tests and early outcomes of acute ischemic stroke in older euthyroid patients. Exp Gerontol 2015; 61: 8-14.

7. Wu GH, Kong FZ, Cheng QZ, Luo WF, Du XD. NTIS predicts severe neurological deficits of cerebral infarction inpatients with large artery artherosclerosis in internal carotid artery system. Neuroendocrinol Lett 2014; 35: 149-53.

8. American Heart Association Stroke Council. Guidelines for the early management of patients with acute ischemic stroke: a guideline for healthcare professionals from the American Heart Association/American Stroke Association. Stroke 2013; 44: 870-947.

9. Ichijo M, Iwasawa E, Numasawa $Y$, et al. Significance of development and reversion of collaterals on MRI in early neurologic improvement and long-term functional outcome after intravenous thrombolysis for ischemic stroke. AJNR Am J Neuroradiol 2015; 36: 1839-45.

10. Bu X, Li C, Zhang Y, et al. Early blood pressure reduction in acute ischemic stroke with various severities: a subgroup analysis of the CATIS trial. Cerebrovasc Dis 2016; 42: 186-95.

11. Wu GH, Kong FZ, Dong XF, et al. Association between hyperhomocysteinemia and stroke with atherosclerosis 
and small artery occlusion depends on homocysteine metabolism-related vitamin levels in Chinese patients with normal renal function. Metab Brain Dis 2017; 32 . 859-65.

12. Li J, Zhao X, Meng X, et al. High-sensitive c-reactive protein predicts recurrent stroke and poor functional outcome: subanalysis of the clopidogrel in high-risk patients with acute nondisabling cerebrovascular events trial. Stroke 2016; 47: 2025-30.

13. Bunevicius A, Kazlauskas $H$, Raskauskiene N, Janusonis V, Bunevicius R. Ischemic stroke functional outcomes are independently associated with C-reactive protein concentrations and cognitive outcomes with triiodothyronine concentrations: a pilot study. Endocrine 2014 45: 213-20.

14. Skvortsova VI, Platonova IA, Shamalov NA, et al. Clinical and immunobiochemical study of efficacy and stress-protective properties of thyroliberin at the acute stage of carotid ischemic stroke. Zh Nevrol Psikhiatr Im S S Korsakova 2006; Suppl 16: 51-9.

15. Sadana P, Coughlin L, Burke J, Woods R, Mdzinarishvili A. Anti-edema action of thyroid hormone in MCAO model of ischemic brain stroke: possible association with AQP4 modulation. J Neurol Sci 2015; 354: 37-45.

16. Mdzinarishvili A, Sutariya V, Talasila PK, Geldenhuys WJ, Sadana P. Engineering triiodothyronine (T3) nanoparticle for use in ischemic brain stroke. Drug Deliv Transl Res 2013; 3: 309-17.

17. Hiroi Y, Kim HH, Ying $H$, et al. Rapid nongenomic actions of thyroid hormone. Proc Natl Acad Sci USA 2006; 103 14104-9.

18. Bunevicius A, lervasi G, Bunevicius R. Neuroprotective actions of thyroid hormones and low-T3 syndrome as a biomarker in acute cerebrovascular disorders. Expert Rev Neurother 2015; 15: 315-26.

19. Shuaib A, Butcher K, Mohammad AA, Saqqur M, Lieb eskind DS. Collateral blood vessels in acute ischaemic stroke: a potential therapeutic target. Lancet Neuro 2011; 10: 909-21.

20. Montagnana M, Lippi G, Targher G, Salvagno GL, Guidi GC. The red blood cell distribution width is associated with serum levels of thyroid stimulating hormone in the gen eral population. Int J Lab Hematol 2009; 31: 581-2.

21. Salloum-Asfar S, Boelen A, Reitsma PH, van Vlijmen BJ. The immediate and late effects of thyroid hormone (triiodothyronine) on murine coagulation gene transcription. PLoS One 2015; 10: e0127469.

22. Utku U, Gokce M, Ozkaya M. Changes in cerebral blood flow velocity in patients with hypothyroidism. Eur J Endocrinol 2011; 165: 465-8.

23. Elbers LP, Moran C, Gerdes VE, et al. the hypercoagulable state in hyperthyroidism is mediated via the thyroid hormone beta receptor pathway. Eur J Endocrinol 2016 Mar 9. pii: EJE-15-1249.

24. Lu M, Yang CB, Gao L, et al. Mechanism of subclinical hypothyroidism accelerating endothelial dysfunction (Review). Exp Ther Med 2015; 9: 3-10.

25. Kang C. Using ultrasound radio frequency technology to assess regression of the structure and function of the carotid artery by radioiodine therapy in hyperthyroidism patients. Arch Med Sci 2015; 11: 1236-43.

26. Aydogdu A, Karakas EY, Erkus E, et al. Epicardial fat thickness and oxidative stress parameters in patients with subclinical hypothyroidism. Arch Med Sci 2017; 13 383-9.

27. Liu Y, Wang D, Redetzke RA, Sherer BA, Gerdes AM. Thyroid hormone analog 3,5-diiodothyropropionic acid promotes healthy vasculature in the adult myocardium independent of thyroid effects on cardiac function. Am J Physiol Heart Circ Physiol 2009; 296: H1551-7.

28. Jakowczuk M, Zalas D, Owecki M. Permanent atrial fibrillation in heart failure patients as another condition with increased reverse triiodothyronine concentration. Neuro Endocrinol Lett 2016; 37: 337-42.

29. Alonso H, Fernández-Ruocco J, Gallego M, et al. Thyroid stimulating hormone directly modulates cardiac electrical activity. J Mol Cell Cardiol 2015; 89: 280-6.

30. Akhoundzadeh K, Vakili A, Sameni HR, et al. Effects of the combined treatment of bone marrow stromal cells with mild exercise and thyroid hormone on brain damage and apoptosis in a mouse focal cerebral ischemia model. Metab Brain Dis 2017; 32: 1267-77.

31. Oliveira KC, da Conceição RR, Piedade GC, et al. Thyroid hormone modulates neuroglobin and cytoglobin in rat brain. Metab Brain Dis 2015; 30: 1401-8.

32. Cheng-Ching E, Frontera JA, Man S, et al. Degree of collaterals and not time is the determining factor of core infarct volume within 6 hours of stroke onset. AJNR Am J Neuroradiol 2015; 36: 1272-6.

33. Schaller B, Graf R. Cerebral ischemia and reperfusion: the pathophysiologic concept as a basis for clinical therapy. J Cereb Blood Flow Metab 2004; 24: 351-71.

34. Fassbender K, Schmidt R, Mössner R, Daffertshofer $M$, Hennerici M. Pattern of activation of the hypothalamic-pituitary-adrenal axis in acute stroke. Relation to acute confusional state, extent of brain damage, and clinical outcome. Stroke 1994; 25: 1105-8.

35. Menon BK, Qazi E, Nambiar V, et al. Differential effect of baseline computed tomographic angiography collaterals on clinical outcome in patients enrolled in the interventional management of stroke III trial. Stroke 2015; 46: 1239-44.

36. Sayan S, Kotan D. Levels of brain natriuretic peptide as a marker for the diagnosis and prognosis of acute ischemic stroke. Arch Med Sci Atheroscler Dis 2016; 1 : e16-22.

37. Arsava EM, Vural A, Akpinar E, et al. The detrimental effect of aging on leptomeningeal collaterals in ischemic stroke. J Stroke Cerebrovasc Dis 2014; 23: 421-6.

38. Chakraborti S, Chakraborti T, Mandal M, Das S, Batabyal SK. Hypothalamic-pituitary-thyroid axis status of humans during development of ageing process. Clin Chim Acta 1999; 288: 137-45.

39. Kilburn-Watt E, Banati RB, Keay KA. Altered thyroid hormones and behavioral change in a sub-population of rats following chronic constriction injury. J Neuroendocrinol 2010; 22: 960-70.

40. Lu Y, Guo H, Liu D, Zhao Z. Preservation of renal function by thyroid hormone replacement in elderly persons with subclinical hypothyroidism. Arch Med Sci 2016; 12: 772-7.

41. Sertbas Y, Sertbas M, Okuroglu N, et al. Mean platelet volume changes before and after glycated hemoglobin (HbA1c) improvement in a large study population. Arch Med Sci 2017; 13: 711-5. 